\title{
Clinical Cases and Serum Biochemical Profiles of Horses Naturally Infected with Dourine in Western Arsi Zone, Ethiopia
}

Yonas Gizaw ${ }^{1^{*}}$, Hagos Ashenafi ${ }^{2}$ and Tilaye Demssie ${ }^{2}$

${ }^{1}$ Jigjiga University College of Veterinary Medicine, PO Box 1020, Jigjiga, Ethiopia

${ }^{2}$ Addis Ababa University College of Veterinary Medicine and Agriculture, PO Box 34, Ethiopia

"Corresponding author: Yonas Gizaw, Jigjiga University College of Veterinary Medicine, PO Box 1020, Jigjiga, Ethiopia, Tel: +2510910417497; E-mail: yonasg5@gmail.com

Rec date: February 21, 2018; Acc date: March 26, 2018; Pub date: March 27, 2018

Copyright: @ 2018 Gizaw Y, et al. This is an open-access article distributed under the terms of the Creative Commons Attribution License, which permits unrestricted use, distribution, and reproduction in any medium, provided the original author and source are credited.

\begin{abstract}
Dourine a venereal transmitted trypanosomosis is endemic in Ethiopia and is the major health problem threatening equines worldwide. A cross-sectional study design and purposive sampling were used from November 2014 to June 2015 to identify clinical cases of dourine infected horses. Twelve mares with typical signs of dourine and serologically positive with CATT/T. evansi were identified. Despite attempts made to isolate the parasite using woo test, no trypanosomes were detected in all of examined blood samples. Among the serum samples which were taken from clinically dourine suspected mares and tested positive using CATT/T. evansi, 10 positive serum samples were selected purposively. Similarly 10 CATT negative serum samples were taken purposively from horses which were apparently healthy and in good body condition as control group. In such a manner serum samples collected were divided into two groups containing 10 negative (apparently healthy group) and 10 positive serum samples. Even though, not significant variation $(p>0.05)$, a relative increase were observed in the mean values of total protein, AST, ALT and ALP while the mean level of albumin showed a relative decrease in infected group compared to healthy one. Therefore, the effect of infection with Trypanosoma equiperdum on the serum biochemicals should be done in the future by increasing sample sizes and considering early/acute and late/chronic stage.
\end{abstract}

Keywords: Dourine; Ethiopia; Mare; Serum biochemicals; Trypanosoma equiperdum

\section{Introduction}

The developing world contains an estimated 90 million equines, with the highest concentrations in central Asia and North and East Africa. More than $95 \%$ of all donkeys and mules and $60 \%$ of all horses on earth are located in developing countries. Ethiopia is one of the leading countries in Africa and in the world with respect to its huge equine population. In a developing country like Ethiopia, the contribution of equines in the sector of transportation and agriculture is of considerable significance [1].

Throughout the world, the one common factor leading to the ill health, suffering and early demise of equines is the protozoan parasite, Trypanosoma equiperdum, causing dourine [2]. Dourine is a contagious disease of equids caused by the protozoan parasite Trypanosoma equiperdum. Once widespread, dourine has been eradicated from many countries but is still seen in horses in Asia, Africa, South America, southern and eastern Europe, Mexico and Russia and was reported in June 2011 in Sicily and then just north of Naples, on the Italian mainland [3].

It is the only trypanosomosis that is not transmitted by bloodfeeding vectors. Unlike other trypanosomal infections, dourine is transmitted almost exclusively during coitus [4]. Dourine can affect horses, mules and donkeys. The latter are generally more resistant and often remain asymptomatic carriers.

Its course and clinical signs vary considerably depending on the virulence of the strain concerned. The course of the disease in horses is chronic, varying from a few months to $1-2$ years. The clinical signs are marked by periodic exacerbation and relapse, ending in death or, possibly, recovery. Fever, local edema of the genitalia and mammary glands, cutaneous eruptions, incoordination, facial paralysis, ocular lesions, anemia, and emaciation may all be observed. Edematous cutaneous plaques, $5-8 \mathrm{~cm}$ in diameter and $1 \mathrm{~cm}$ thick, are pathognomonic [5]. Trypanosoma equiperdum differs from other trypanosomes in that it is primarily a tissue parasite that rarely invades the blood. The trypanosomes, which are present in the seminal fluid and mucous membranes of the genitalia of the infected donor animal, are transferred to the recipient during sexual intercourse. Parasites then may pass into the blood, where they are carried to other parts of the body. In typical cases, this metastatic invasion gives rise to characteristic cutaneous plaques $[2,6]$.

The constant antigenic variations of the parasite results in the release of large amount of biological active products and the formation of immune complexes, which are certainly major factors in triggering a variety of clinical and pathological changes [7]. When animals become infected with trypanosomosis, their physiology alters [8]. This is due to the wide range of blood biochemical changes [9]. The evaluation of blood indices and parameters helps to determine the health status of animals and also to establish the degree of damage to hosts tissues as well as the severity of the infection [10].

Dourine is endemic in Ethiopia with seroprevalence of greater than $28 \%$ and is considered the most important health problem threatening equines in most parts of the world [11]. Although dourine represents one of the most severe diseases of horses responsible for marked economic losses, few studies have been done on dourine in Ethiopia [11-14]. 
The literature on this topic is generally old and lacking evidence, as this disease is not generally present in developed countries. Attempt for isolation of T. equiperdum is very difficult, as demonstrated by the low number of isolates in the past decades. Moreover, dourine is a chronic disease whose signs are not constantly present and whose pathogenicity can vary, depending on the strain concerned. Though dourine still occurs in many parts of the world, since its eradication from North America and northern Europe, published research on the pathology, pathogenesis, immunology and chemotherapy of the disease has been neglected. There is remarkable deficiency in our current knowledge of the pathology of the disease. In line with the above background information and justifications, the main aim of the present study was:

To investigate clinical cases, serum biochemical alteration and presence of Trypanosoma equiperdum in blood of dourine infected mares.

\section{Materials and Methods}

\section{Study area}

The present study was carried out in two dourine prevalent or endemic foci districts namely Dodola and Assassa located in the Western Arsi highlands of Oromia regional state, Ethiopia. Dodola is located in the West Arsi Zone, $320 \mathrm{~km}$ away from the capital Addis Ababa, at $6.983^{\circ} \mathrm{N}$ latitude and $39.183^{\circ} \mathrm{E}$ longitude with an elevation ranging from 2,362 to 2,493 $\mathrm{m}$ above sea level. Assassa is also located in West Arsi Zone, about $300 \mathrm{~km}$ South from Addis Ababa with geographical coordinates are $7.2^{\circ} \mathrm{N}, 39.2^{\circ} \mathrm{E}$, with an elevation 2,600 to 2,650 $\mathrm{m}$ above sea level. Agriculture is the mainstay of the livelihood of peoples and the leading economic activity of the area with a mixed farming system covering the highest percentage of the total agricultural activities with crop-livestock production [15]. Equine population is the highest in Oromia region mainly of the Arsi-Bale highlands [16].

\section{Study population}

Animals considered in this study are sexually mature adult horses and which are suspected of naturally infected with Trypanosoma equiperdum showing typical clinical signs of dourine, living under a traditional management system of free grazing.

\section{Study design and sampling method}

A cross-sectional study design and purposive sampling method were used to identify horses showing typical clinical signs of dourine from November 2014 to June 2015. Horses present in the study area were examined clinically for the presence of typical signs of dourine and were then followed by sample collection and laboratory examination.

\section{Clinical examination}

Careful and systematic clinical examinations of sexually matured horses in the study area were done. Special attentions were given to the body condition, skin, external reproductive genitalia and nervous system. During field observation detail records about history, sex, age, observed signs and body condition of the animals were recorded. In addition, a detailed physical examination of horses including the measurement of the vital parameters (temperature, heart and respiratory rate) was conducted. Infected animals showing signs of dourine were tested parasitologically as well as, serologically using buffy coat examination and Card Agglutination Test for Trypanosomosis (CATT/ T. evansi) respectively.

\section{Blood collection}

Blood samples were collected from the jugular vein of horses and showing sign of dourine twice using plain for serological and serum biochemical test and heparinized vacutainer tubes and needles for parasitological examination, after the site had been wiped with cotton wool soaked in alcohol.

\section{Parasitological examination}

Haematocrit centrifugation technique (mHCT) was used to isolate the parasite from blood. Two capillary tubes with an internal diameter of $1 \mathrm{~mm}$ were filled with blood up to three-fourth $(50 \mu \mathrm{l})$ of the capacity and centrifuged for 5 minutes in micro-centrifuges at maximum 12,000 rpm. The capillary tubes are then mounted in a viewing slide and the buffy coat plasma interface layers were examined at magnification of 10x under microscope as described by Woo [17] and Reid [18] to look for live parasites.

\section{Serological examination}

The CATT/RoTat 1.2 serological test was performed at field level which is considered as a rapid field screening tests in accordance with [4]. The antigen and buffer of CATT/T. evansi test was obtained from VLIR OUS Ethio- Belgium Team Project laboratory. It is a rapid direct agglutination test, which uses formaldehyde fixed, Coomassie stained, freeze-dried trypanosomes of T. evansi VAT RoTat 1.2. In the CATT/ T. evansi test, $30 \mu \mathrm{l}$ of sera diluted two-fold with PBS were mixed with $30 \mu \mathrm{l}$ of reagent on a test card. The reagent and test serum were mixed, spread over approximately $1.5 \mathrm{~cm}$. The tests were then checked with positive and negative controls before the whole samples were tested. The presence of antibodies was revealed by macroscopic agglutination at a dilution of 1:8 [19,20].

\section{Serum biochemical profile analysis}

Serum biochemical tests were performed on serum samples prepared from whole blood collected using plain vacutainer tubes, centrifuged at $3200 \mathrm{rpm}$ for 10-15 minutes after 1-2 hours of collection and stored at $-20^{\circ} \mathrm{C}$ until analysis is performed. Among the serum samples which were taken from clinically dourine suspected mares and tested positive using CATT/T. evansi, 10 positive serum samples were selected purposively. Similarly 10 CATT negative serum samples were taken purposively from horses which were apparently healthy and in good body condition as control group. In such a manner serum samples collected were divided into two groups containing 10 negative (apparently healthy group) and 10 positive serum samples. Serum samples were then tested using humaStar 80 clinical chemistry analyzer according to Reitman [21] and Human Gmbh (Wiesbaden, Germany) standard commercially available Kits according to the manufacturer's instruction to determine the concentration of total protein, albumin, aspartate aminotransferase (AST/GOT), (ALT/GPT) and alkaline phosphatase (ALP) in the two groups at Addis Ababa University College of Veterinary Medicine and Agriculture (AAUCVMA) physiology and biochemistry laboratory. 


\section{Statistical Analysis}

The data collected from the study animals were coded, entered and stored in MS excel spread sheet. The collected results of serum biochemical test were also entered into Microsoft excel spread sheet and the data were analyzed using SPSS version 20 software (SPSS, 2011). The mean values of the various serum biochemicals in the two groups were analyzed using independent student t-test. Statistically significant difference were said to exist if $\mathrm{p}<0.05$.

\section{Results}

\section{Clinical cases}

Mares positive for T. equiperdum showed combinations of various characteristic clinical signs of dourine. The details of the combinations of the clinical signs were indicated in Table 1 . In Table 2 , a value ( 0 or 1 ) is attributed to a given sign in each mare on the basis of its presence (1) or absence (0). So that, it helps to establish which signs of the disease were most common and occur at the same time. The percentage of specific sign were calculated by dividing the total number of specific signs observed in each mare by total number of infected mares and multiplied by 100 .

\begin{tabular}{|c|c|c|c|c|c|c|}
\hline & \multicolumn{3}{|c|}{ Genital signs } & \multicolumn{2}{|c|}{ Cutaneus signs } & \multirow{2}{*}{$\begin{array}{l}\text { Nervou } \\
\text { s signs }\end{array}$} \\
\hline $\begin{array}{l}\text { Naturally } \\
\text { infected } \\
\text { animals }\end{array}$ & $\begin{array}{l}\text { Edem } \\
\text { a of } \\
\text { the } \\
\text { vulva }\end{array}$ & $\begin{array}{l}\text { Emaciatio } \\
\mathrm{n}\end{array}$ & $\begin{array}{l}\text { Depigementatio } \\
\mathrm{n} \text { around } \\
\text { genitalia }\end{array}$ & $\begin{array}{l}\text { Edema } \\
\text { of } \\
\text { mammar } \\
\text { y gland }\end{array}$ & $\begin{array}{l}\text { Ventra } \\
\text { I } \\
\text { edema }\end{array}$ & \\
\hline M1 & 0 & 1 & 1 & 1 & 0 & 1 \\
\hline M2 & 1 & 1 & 1 & 0 & 0 & 1 \\
\hline M3 & 1 & 1 & 1 & 0 & 0 & 1 \\
\hline M4 & 1 & 1 & 0 & 1 & 1 & 1 \\
\hline M5 & 0 & 1 & 0 & 0 & 0 & 1 \\
\hline M6 & 1 & 1 & 1 & 0 & 1 & 1 \\
\hline M7 & 0 & 1 & 0 & 0 & 0 & 1 \\
\hline M8 & 1 & 1 & 1 & 1 & 0 & 1 \\
\hline M9 & 0 & 1 & 0 & 0 & 0 & 1 \\
\hline M10 & 1 & 1 & 0 & 0 & 0 & 1 \\
\hline M11 & 0 & 1 & 1 & 0 & 0 & 1 \\
\hline M12 & 0 & 1 & 0 & 0 & 0 & 1 \\
\hline Total & $50 \%$ & $100 \%$ & $50 \%$ & $25 \%$ & $17 \%$ & $100 \%$ \\
\hline
\end{tabular}

Table 1: Clinical signs encountered in infected mares.

Emaciation or Weight loss: All animals with clinical signs of dourine were emaciated, weak and were in the state of poor body condition. Inelastic skin and a dull coat with numerous grazes around protruding bones were observed. There was no appetite loss in any of the cases during examination and as complained by the animal owners.
Genital signs: Edema of the external genitalia and depigmentation of skin commonly around the vulva but extending to the skin of tail in some cases (Figure 1A) and scars over the external genitalia, were the prominent signs observed in the genital form of the disease In some mares, there were ulcers on the labia and clitoris (Figure 1B) and vaginal discharges in some others (Figure 1C).

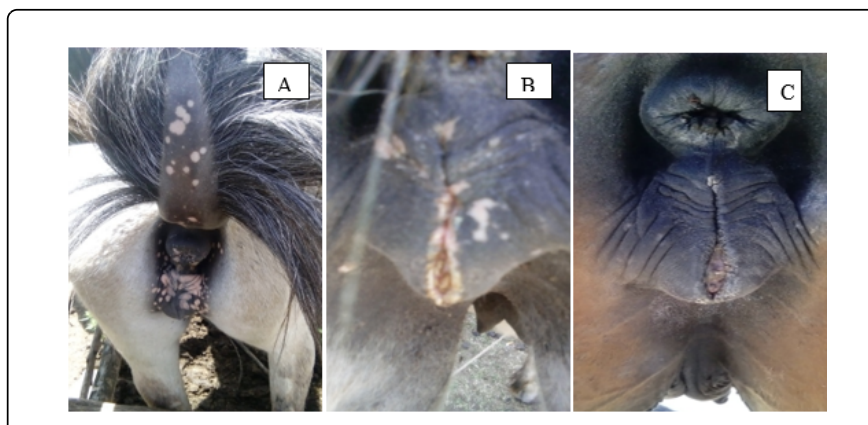

Figure 1: Genital signs (A) Depigmentation in the perineal region and swollen vulva (B) Ulcerated lesion of labia and clitoris (C) Mucopurulent vaginal discharge.

Edema of the mammary gland and ventral abdomen: Few of infected mares showed non-painful edema of the mammary glands and yellowish serum-like mammary secretion. Similarly, few mares showed ventral edema that extends from the sternum region to the umbilical area. In this study cutaneous wheals and plaques that are considered as important sign of cutaneous form of the disease were not observed in any of the positive mares (Figure 2).

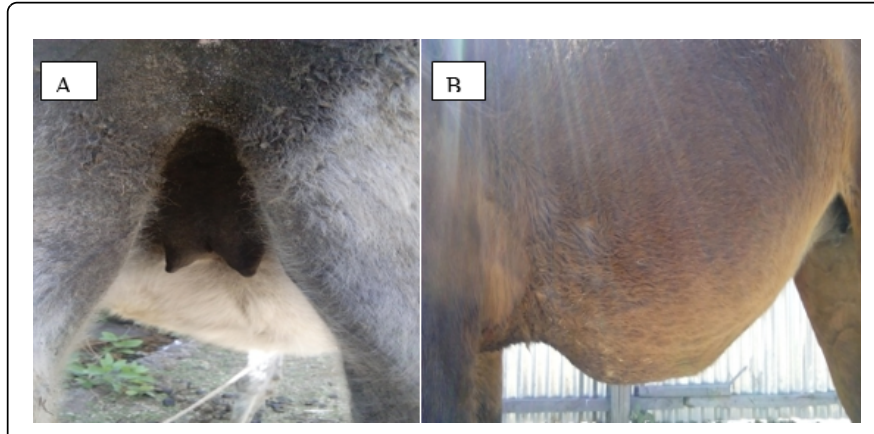

Figure 2: Edema (A) Edema of the mammary gland (Non lactating mare) (B) Ventral edema (Mare).

Nervous signs: Neurological signs include difficulty in walking with marked ataxia of hindquarters and spreading of the limbs. The left hind leg of animals often dragged on the ground with straddle gait with the hind legs held apart, particularly when trying to walk forward.

\section{Demonstration of the parasite and serology}

Even though several attempts has been made to isolate the parasite in the buffy coat examination using Woo test of blood samples from clinically and serologically (CATT/T evansi) positive horses, no trypanosomes detected in all examined blood samples. From the total of twenty (20) clinically suspected horses, twelve (12) mares were found positive serologically using CATT/ T. evansi test. 


\section{Serum biochemical profile changes}

The mean serum level and significance (p-value) of difference for total protein, albumin, AST, ALT and ALP of the clinically negative and CATT negative and clinically positive and CATT positive serum samples are indicated in Table 2. Even though, it is not significant $(\mathrm{P}>0.05)$, it has been observed that there was a relative increase in the mean level of serum total protein, AST, ALT and ALP in clinical and serological positive serum samples when compared to the clinical and serological negative serum samples. However, the mean level of albumin is higher in the clinical and serological negative serum samples compared to positive serum samples, even though the difference was not statistically significant $(\mathrm{P}>0.05)$.

\begin{tabular}{|l|l|l|l|}
\hline \multicolumn{4}{|c|}{ Mean values \pm SD } \\
\hline $\begin{array}{l}\text { Serum biochemical } \\
\text { tests }\end{array}$ & CATT negative & CATT positive & P-value \\
\hline Total protein (g/dl) & $6.7 \pm 0.83$ & $6.94 \pm 0.96$ & 0.557 \\
\hline Albumin (g/dl) & $2.81 \pm 0.32$ & $2.74 \pm 0.45$ & 0.694 \\
\hline AST (U/L) & $273.47 \pm 60.9$ & $320.68 \pm 135.36$ & 0.338 \\
\hline ALT (U/L) & $18.57 \pm 10.04$ & $26.00 \pm 10.78$ & 0.128 \\
\hline ALP (U/L) & $503.86 \pm 128.6$ & $636.95 \pm 177.45$ & 0.071 \\
\hline
\end{tabular}

Table 2: Mean \pm SD of serum biochemicals profiles of the clinically and CATT positive mares and clinically and CATT negative horses.

\section{Discussion}

The results of the present study indicate that most of the signs and lesions observed coincide with those reported in the few available literature studies. All mares with clinical sign of dourine were emaciated, weak and are in poor body condition even though, there was no appetite loss. This was in agreement with previous reports of Alemu [13] and Hagos [14] from the study area and Pascucci [22] and Vulpiani [23] from Italy. Vulpiani et al. indicated that weight loss is one of the early signs that could lead the veterinarian or owner to suspect dourine [23].

Genital form of the disease which includes depigmentation of vulval skin, edema of the vulva, ulcer on labia and mucopurlent discharge were seen in some infected mares usually together with nervous sign were in agreement with previous literatures $[13,14,22,23]$.

Edema of the mammary glands and ventral region were seen in a relatively few cases. This sign was not constant sign observed, probably because some of the mares were in the first and third stage of the disease, when it is not present or might be due to difference in the host response to infection. Skin plaques or wheals, which are regarded as important symptoms in cases of dourine were not observed in this investigation. However, plaques are a rare symptom and they can be observed in comparatively few cases [4]. This finding was in line with Alemu [13] and Hagos [14] who reported the presence of edema of mammary gland and ventral edema and absence of skin plaques in $T$. equiperdum infected horses in Ethiopia. However, Pascucci [22] stated the presence of skin wheals in few cases and Vulpiani [23] reported skin plaques in most of the infected horses studied.

The nervous signs such as difficulty in walking, marked ataxia of hindquarters and spreading of the limbs without sensory alterations in infected horses reported in the present study were in line with literatures and seems to confirm the tropism of T. equiperdum for the peripheral nervous system and lack of involvement of the central nervous system, in contrast with other trypanosomes [22,24,25].

The most commonly observed clinical signs in the present study are the genital and nervous signs of dourine while the cutaneous signs of the disease were not prominent. This is in argument with Pascucci [22] and Vulpiani [23] who reported the second phase (cutaneous signs) and third phase (nervous signs) are the common and prominent signs. This difference might be due to the difference in the strain of the parasite, breed of horse, nutrition and stress factor. This is supported with many authors that stated clinical signs and pathogenecity of dourine vary with breed of host, the virulence of the strain, the nutritional status of the horse, and stress factors $[2,6,26,27]$.

In this study no stallions showing typical sign of dourine were observed. This might be due to stallions were presented to the clinic by the owners in the late stage of the disease when the clinical signs disappeared and are mostly asymptomatic. This is supported with the observation of Vulpiani [23] that states the infected stallions revealed mild signs than in the infected mares. Six months after infection, the stallions were almost asymptomatic. However, the possibility of difference in susceptibility to infection with regard to sex is not described in the study due to small sample size used and yet not known.

It was not possible to isolate the parasite from the blood of infected horses showing clinical evidence of infection with T. equiperdum by buffy coat examination despite the several attempts have been made. This could be due to the low number of parasites normally present in infected tissues and the mild, short-lasting parasitemia [2,22,26]. T. equiperdum is considered primarily a tissue parasite in nature and rarely found in the blood [2,6]. According to literature, these diagnostic difficulties are typically due to disease caused by $T$. equiperdum [3].

Despite these difficulties and failure to isolate T. equiperdum in the present and some previous studies, [28] Fikru isolated the parasite from the blood of two clinically sick horses in Dodola, Ethiopia. Over the past decades the difficulty of isolating T. equiperdum from infected horses made its characterization and differentiation within the sub genus trypanozoon a problem, and still identification is made on those strains maintained in laboratory animals [29].

The mean values of the serum biochemical parameters analyzed in this study for both positive and non-infected horses were within the normal reference values established for working equids of Ethiopia [30]. There was no significant difference in the total protein level observed between infected and healthy horses. Similar results were documented by Marques et al. [31] in horse experimentally infected with $T$. evansi. Despite these, there is relative increase in total protein and decrease in albumin in infected horses compared to non-infected. The increase in protein levels during the chronic phase of the infection is usually due to the increase in globulin levels as a result of the immune response (humoral) by the animals to the infection [32]. Hyperglobulinemia coupled with by hypoalbuminemia in donkeys experimentally infected with $T$. evansi was also reported by Cadioli et al. [33].

Increase in AST and ALT activity has been reported in T. evansi infected camels [34]. The rise in AST activity can be attributed partly to cellular damage caused by the trypanosomes lysis, while the increase in ALT activity probably results from host destruction of 
trypanosomes [35]. Compared with the previous report in which, AST, ALT and ALP enzymes displayed significant increase during trypanosomosis [36] in the present study, no significant changes were observed in these enzymes of infected horses despite the relative increase in infected horse compared to healthy group. These might occur due to the possibility that most of serologically positive mares included in the analysis might be in the early stage of the disease at time of examination when there is no sever organ damage as the CATT/T. evansi does not differentiate early and late infection. These findings are in accordance with the works of Chaudhary [37] in camels naturally infected with trypanosomosis and in camels infected with $T$. evansi reported no significant changes in these enzymes level [38].

\section{Conclusion}

Due to the extreme variability of signs in infected horses affected with dourine, difficulties in clinical diagnosis and knowledge gap on the disease, it is important to observe and study new cases of dourine. The serum biochemical analysis in the present study indicates that $T$. equiperdum infection caused a statistically non-significant alteration in the serum biochemical parameters in infected mares compared to healthy one. However, these doesn't mean that the disease don't cause damage to the vital organs but the serum biochemical figure observed in this study could arise from variation in the stage of the disease among the infected mares causing an inter individual variation. Difficulty in isolating the parasite from blood and other body fluids should initiate professionals in the area. The effect of infection with Trypanosoma equiperdum on the serum biochemicals should be done in the future by increasing sample sizes and considering early/acute and late/chronic stage.

\section{Acknowledgements}

The author would like to thank Dodola veterinary clinic technicians for the logistic support and passionate encouragement during the field work. The CATT/T. evansi tests were supplied from Addis Ababa University Ethio-Belgium VLIR-UOS team project.

\section{References}

1. Pritchard JC, Lindberg AC, Main DCJ, Whay HR (2005) Assessment of the welfare of working horses, mules and donkeys, using health and behavioral parameters. Prev Vet Med 69: 265-283.

2. Stephen LE (1986) Trypanosomiasis, a veterinary perspective. 1st edn, Pergamon Press, Oxford, UK.

3. Sidney R, Andrew McG, James C, Richard N (2013) Dourine - an emerging venereal threat to European horses. AHT/BEVA/DEFrA Equine Quarterly Disease Surveillance report 6, 7.

4. Claes F, Agbo EC, Radwanska M (2003) How does T. equiperdum fit into the Trypanozoon group? A cluster analysis by RAPD and multiplexendonuclease genotyping approach. Parasitology 126: 425-431.

5. Claes F, Büscher P, Touratier L, Goddeeris BM (2005) Trypanosoma equiperdum: master of disguise or historical mistake? Trends Parasitol 21: 316-321.

6. Hoare CA (1972) The trypanosomes of mammals. Blackwell scientific publications, Oxford.

7. Zwart D (1989) Aspects of comparative pathology and pathogenesis of Trypanosomal infections in Africa. Ann Soc Belge Med Trop 69: 105-112.

8. Biryomumaisho S, Katunguka-Rwakishaya E, Rubaire-Akiiki CM (2003) Serum biochemical changes in experimental T. congolencse and T. brucei infection in small east African goats. Vet Arhiv 73: 167-180.

9. Katunguka-Rwakishaya E (1996) The prevalence of trypanosomosis in small ruminants and pigs in a sleeping sickness endemic area of Buikwe country Mukono district, Uganda. Revd' Elev Med Vet Pays Trop 49: 56-58.

10. Otesile EB, Fagbemi BO, Adeyemo O (1991) The effect of T. brucei infection on serum biochemical parameters in boars on different planes of dietary energy. Vet Parasitol 40: 207-216.

11. Clausen PH, Gebreselassie G, Abditcho S, Mehlitz D, Staak C (1999) Detection of Trypanosoma DNA in serological positive but aparasitemic horses suspected of dourine in Ethiopia. Tokai J Exp Clin Med 23: 303-308.

12. Zeleke D, Ketema S, Abdul S (1980) An investigation of dourine in Arsi Administrative Region. Ethiop Vet Bull 4: 3-19.

13. Alemu T, Luckins AG, Philips LP, Reid SWJ, Holmes PH (1997) The use of ELISA to investigate the prevalence of T. equiperdum in Ethiopian horses. Vet Parasitol 71: 239-250.

14. Hagos A, Abebe G, Buscher P, Goddeeris BM, Claes F (2010) Serological and parasitological survey of dourine in the Arsi-Bale highlands of Ethiopia. Trop Anim Health Prod 42: 769.

15. Arsi-Bale Zone Agricultural and Rural Development Office (2009) Annual Meteorological and livestock report, Robe, Ethiopia.

16. Arsi-Bale zone plan office (2006) Zonal Agricultural Compiled Report, Oromia region, Ethiopia, pp. 7-11.

17. Woo PTK (1970) The haematocrit centrifuge technique for the diagnosis of African Trypanosomasis. Acta Trop 27: 384-386.

18. Reid SA, Husein A, Copeman DB (2001) Evaluation and improvement of parasitological tests for T. evansi infection. Vet Parasitol 102: 291-297.

19. Bajyana S, Hamers R (1988) A card agglutination test (CATT) for veterinary use based on an early VAT RoTat 1.2 of T. evansi. Ann Soc Belge Med Trop 68: 233-240.

20. Verloo D, Magnus E, Buscher P (2001) General expression of RoTat 1.2 variable antigen type in Trypanosoma evansi isolates from different origin. Vet Parasitol 97: 183-189.

21. Reitman S, Frankel S (1957) A calometric method for the determination of serum glutamic oxaloacetic and glutamic pyruvic transaminases. Am J Clin Pathol 28: 56-62.

22. Pascucci I, Andrea D, Cesare C, Gabriella D, Paolo C, et al. (2013) Diagnosis of dourine in outbreaks in Italy. Vet Parasitol 193: 30-38.

23. Vulpiani MP, Carvelli A, Giansante D, Iannino F, Paganico D, et al. (2013) Reemergence of dourine in Italy: clinical cases in some positive horses. J Equi Vet Sci 33: 468-474.

24. Barrowman PR (1976) Experimental Intraspinal T. equiperdum Infection in a Horse. Orderstepoort J Vet Res 43: 201-202.

25. Berlin D, Loeb E, Baneth G (2009) Disseminated central nervous system disease caused by T. evansi in a horse. Vet Parasitol 161: 316-319.

26. OIE (2008) Dourine. In: Manual of diagnostic tests and vaccines for terrestrial animals. Office International des Epizooties (OIE), Paris, France, pp: 845-851.

27. Zablotskij VT, Georgiu C, De Waal TH, Clausen PH, Claes F, et al. (2003) The current challenges of dourine: difficulties in differentiating $T$. equiperdum within the subgenus Trypanozoon. Rev Sci Tech Off Int Epiz 22: 1087-1096.

28. Fikru R, Hagos A, Alemu T, Filip C (2010) Comparative diagnosis of parasitological, serological, and molecular tests in dourine-suspected horses. Trop Anim Health Prod 42: 1649-1654.

29. Wei Y, Wen Y, Desquesnes M, Zhao-Rong L (2011) Molecular epidemiology of $T$. evansi and T. equiperdum and atypical human infection by animal trypanosomes. Madame Curie Report $\odot$, Landes Bioscience.

30. Simenew K, Gezahegne M, Getachew M, Wondyefraw M, Alemayehu L, et al. (2011) Reference values of clinically important physiological, hematological and serum biochemical parameters of apparently healthy working equids of Ethiopia. Global Veterinaria 7: 1-6.

31. Marques LC, Machado RZ, Alessi AC, Aquino LPCT, Pereira GT (2000) Experimental infection with $T$. evansi infection in horses: clinical and hematological observations. Rev Bras Parasitol Vet 9: 11-15. 
Citation: Gizaw Y, Ashenafi H, Demssie T (2018) Clinical Cases and Serum Biochemical Profiles of Horses Naturally Infected with Dourine in Western Arsi Zone, Ethiopia. J Vet Sci Technol 9: 528. doi:10.4172/2157-7579.1000528

Page 6 of 6

32. Orhue NEJ, Nwanze EAC, Okafor A (2005) Serum total protein, albumin and globulin levels in T. brucei-infected rabbits: Effect of orally administered scoparia dulcis. Afr J Biotech 4: 1152-1155.

33. Cadioli FA, Marqus LC, Machado RZ, Alessi AC, Aquino LP, et al. (2006) Experimental T. evansi infection in donkeys: hematological, biochemical and histopathological changes. Arq Bras Med Vet Zootec 58: 749-756.

34. De La Rue ML, Carli GA, De Herrera HM, Silva RAMS (1997) Biochemical changes in acute infection of dogs with T. evansi. J Protozool Re 7: 28-35.

35. Enwezor FNC, Sackey AKB (2005) Camel trypanosomiasis-a review. Vet Arch 75: 439-452.
36. Rahman ZU (1992) Serum biochemical, enzymes and haematological changes in one-humped camels infected with Surra. Proceedings of the first international camel conference, R \&W Publications Limited, Dubai, p: 405.

37. Chaudhary ZI, Iqbal J (2000) Incidence, biochemical and haematological alterations induced by natural trypanosomosis in racing dromendary camels. Acta Trop 77: 209-213.

38. Gutierrez C, Corbera JA, Juste MC, Doreste F, Morales I (2005) An outbreak of abortions and high neonatal mortality associated with $T$. evansi infection in dromedary camels in the Canary Islands. Vet Parasitol 130: 163-168. 